Ian Butter BSc FRICS

is a chartered surveyor and director of planning at the specialist practice Humberts Leisure of Mayfair and regional offices. A former chairman of the RICS Planning Division for the North West Region and Lancashire Branch chairman, he advises on leisure and tourism planning proposals throughout the country for national and international concerns.

Keywords:

future, government, leisure, planning, policy, trends
Ian Butter

Humberts Leisure,

Tom Hill House,

Broughton,

Skipton, Yorkshire BD23 3AQ, UK

Tel: +44 (o) 1756799271

Fax: +44 (o) 1756700811

E-mail: ian.butter@humberts-

leisure.com

\section{Planning ahead! Understanding the government's future leisure planning policy}

\author{
lan Butter \\ Received (in revised form): 11 June 2001
}

\begin{abstract}
This paper considers the way in which the leisure industry has affected, and is affected by, government planning policy, highlights some of the key changes and attempts to assess the likely future trends for the leisure industry from a planning perspective.
\end{abstract}

\section{INTRODUCTION}

The trouble with the leisure industry is that it is just too diverse for its own good. Whether your particular leisure pastime involves simply a walk in the park, or activities at a multi-million pound pleasure dome, the spread of leisure opportunities and its associated property development involves the town planning system to a greater or lesser extent at almost every stage.

To add further complication, there remains the question of defining exactly what 'leisure' means to the developer. In the property press one would be forgiven for assuming that the leisure industry extended to no more than cinemas, pubs, clubs and hotels. From a tourist industry perspective, however, the view broadens to include a plethora of additional leisure products, including dayvisitor attractions, heritage landscapes and even the humble public footpath - the role of which has been brought into sharp focus from a tourism perspective during the recent foot-and-mouth crisis.

The trouble is, there is no way to categorise 'leisure' into a single use class because it is so diverse, and therefore the government's policy draftsmen continue to find 'leisure' a difficult and complex area within which to legislate. If all that was not bad enough, there is the increasing trend for the assimilation of leisure uses with more mainstream land uses, each with its own distinct development criteria.

\section{THE PAST}

In an endeavour to crystal ball gaze into the future, it is useful to consider briefly the pace of change that has occurred in planning policy terms over the last ten to 15 years. The substantial redrafting and consolidation of the Town and Country Planning Acts in 1990 coincided with the height of the development boom of the 1980s and the reawakening of the global environmental agenda following the Rio Summit in 1989. The subsequent raft of legislative changes 
A tidal wave of planning guidance since 1990 has been unprecedented since the introduction of the planning system in 1947.

Despite the recession, a cash-rich population, with leisure time on its hands, brought about a previously unseen surge in leisurerelated development. Traditional leisure operators began to adapt and diversify their brands, with new products rapidly entering the market.

Before 1990 the developer had the benefit of the doubt in planning terms and there was little in the way of distinct planning policy guidance for the leisure industry. The Use Classes Order which was reviewed in 1987 - began to tackle the knotty problem of food and drink uses and remodelled the Hotels Class to include hostels, although this was subsequently changed again in 1994 because of the impact hostelling was beginning to have on the tourist industry.

Apart from that, there was some reference to the holiday caravan parks industry in Development Control Policy Note 8 and the tentative emergence of some strategic policy thinking within structure and local plans. However, this was largely directed at leisure uses within the tourism sector.

Since 1990 it has been all but impossible for even the most dedicated practitioner to keep pace with the tidal wave of planning guidance. Proposals must now comply with the 'development plan', and the developer no longer enjoys a preferential position in planning decisions. It is for the developer to justify his proposals fully against all the relevant legislative and planning policy hurdles that are placed in front of him.

Until very recently, planning policy has remained largely reactive rather than proactive. However, there have been a number of significant changes in the last few years that have seen planning policy amendments beginning to direct leisure development for the future.

\section{THE PRESENT}

There are four fundamental town planning elements that are shaping property development in this country and which provide a cornerstone for the consideration of future proposals.

\section{Development plans}

The term 'development plan' encapsulates all those planning policy documents that are applied to any one particular area of the country and which form the foundation for development control decisions. At the top one might now reasonably include regional planning guidance, which applies a general strategic approach to the economic development of the regions and is currently in the process of being established by the regional development authorities.

Regional guidance is then interpreted at a county or unitary authority level within structure plans (or Unitary Development Plan 


\section{A rapid pace of change}

\section{Development plan impact not yet fully appreciated}

Part 1s) which provide more specific strategic guidance within the broad regional framework. This strategic policy framework is then translated into a more detailed set of policy provisions at a local level within district-wide local plans and Unitary Development Plan Part 2s.

Each of these documents is prepared and considered within the context of the continuing shower of government Acts, regulations and orders and guidance notes. The whole is then subject to consideration and interpretation by way of the planning appeal process and even 'on-the-hoof' changes in political thinking.

Ministers have an increasing tendency to outline their requirements in public speeches, which may then be taken into account within the planning process as a 'material consideration' well ahead of draft legislation being produced.

This rapid pace of change inevitably leaves councils and developers alike floundering in the wake of change. Development plans are in a constant state of flux and increasingly out of date before they are finally adopted. For example, recent government changes in their approach to future housing provision have left a number of local plans stalled pending further research, with others to be redrafted as they no longer accord fully with the latest government thinking.

Section 54A of the Town and Country Planning Act requires that all development proposals shall accord with the guidance set out in development plans. Although other material circumstances may be taken into account, it is fair to assume that there must be well-substantiated and overriding reasons to permit development which runs counter to the adopted policy.

The leisure industry (along with many others, it has to be said) has yet to appreciate fully the impact that the development-plan-led system will have on future development initiatives, and with many development plans now at their second or third review, policy stances are hardening through lack of a proper challenge.

There are two principal trends. First, there is an increasing tendency for development plans to drive the industry through their policy framework, by allocating development sites, discouraging development in targeted areas and specifying the form and extent of development in ever-increasing levels of detail. Secondly, where there is a need for the plan to be altered in order to afford development opportunities, the process can take many years, requiring a much longer outlook than before. For an industry that thrives on its dynamic ability to change rapidly with its market, the development plan system is a natural barrier to progress, demanding a more acute awareness of opportunities and constraints.

\section{Sequential testing}

As a by-product of the development-plan-led system, leisure property development is increasingly being assessed against 


\section{Planning is increasingly driving the leisure market}

\section{Sustainability is the watchword}

\section{Economic value highlighted}

sequential tests. Simply put, each and every proposal must be judged against the potential for a similar scheme to be provided elsewhere within the vicinity, on available sites closer into the town or city centre. Development proposals are then considered on a concentric ring basis emanating from the centre. The developer must show that there are no more suitable sites available than the one under consideration, having regard to all other matters.

This approach to planning has emerged rapidly over the last few years, driven by the government's desire to reduce greenfield development and regenerate urban areas. With sites for all types of property development now being allocated and detailed in local plans, the market is increasingly being driven by planning rather than commerce. As a result, developers are rapidly reassessing their approach to land buying, having been taken somewhat unawares by the rapid pace of change.

The first to experience sequential testing following changes to Planning Policy Guidance Note 6 have been the urban leisure parks. Hotels appear to be rapidly following suit. There has even been some suggestion that proposals for public houses should be similarly subject to sequential testing, although the extent to which this will apply is now debatable in the light of recent appeal decisions.

\section{The environment}

Few can have failed to appreciate the rapid rebirth of the green agenda during the 1990s, to a point where it is seen by many as being the overriding factor in all planning decisions. Sustainability is now the watchword, resulting increasingly in development limitations. The sequential test is directly associated with protection of the environment - use the worst, most central, urban land first. A reasonable philosophy, perhaps, but not always relevant to the leisure sector.

The preservation of the countryside for its own sake and the desire to reduce travel by car has a variable impact throughout the leisure industry, which may often result in internal conflict within the industry. Those parts of the leisure industry which rely on access to the countryside and 'the right to roam' see the imposition of often draconian development limitations as a positive benefit. Others who thrive on attracting car-borne visitors out from the towns and cities are increasingly concerned that planning policy is effectively cutting their business out from under their feet.

This particular issue was brought home vividly as a result of the downturn in the fortunes of rural leisure businesses following the foot-and-mouth epidemic. Dramatic though the impact has been, the crisis has focused attention on the very real value of the leisure industry to the countryside's economy; a fact that has been largely ignored up to now.

Even in urban areas the green agenda is beginning to impact on leisure development, particularly as a result of the introduction of environmental impact assessments in 1999. All planning 


\section{Timescale and costs are increasing}

\section{Brownfield competition may price leisure out}

applications are now assessed against EIA criteria and, subject to this assessment, development proposals may need to be accompanied by a report detailing the total impact of the proposed development on its surroundings. The lengths to which this can extend are often considerable and inevitably increase the time, cost and scope for progressing any proposal.

The drive to develop urban brownfield sites in favour of greenfield locations is a government priority; so too is the encouragement for development to be clustered around transport nodes. Both seek to promote a move away from the car and a reduction in the use of scarce land resources. The regeneration of brownfield sites is commendable on face value, but often fraught with expensive technical and practical difficulties in reality.

The demand for urban sites now comes from all property sectors, in particular housing. As the number of developable sites reduces so land price rises can be anticipated and potentially the 'pricing out' of leisure schemes can occur, unless they form part of a mixed development. Town-centre redevelopment may delay this eventuality, but the needs of the housing market are likely to take precedence and there is a natural potential for conflict between residential use and some forms of leisure.

\section{Europe}

Perhaps the most noticeable aspect of European legislation from a planning perspective has been the introduction of environmental impact assessments. The EC Directive on Environmental Impact Assessment was originally published in 1985 and, although regulations have been in place since 1988, their formal imposition within development control has only fully emerged in the 1999 Regulations.

European monitoring of bathing-beach water quality, air quality etc all have indirect effects upon the leisure industry to some extent.

Proposals have already been floated suggesting a Europe-wide integration of the planning system, although this remains at the speculative stage and may ultimately depend upon whether Britain fully enters the EU. There is little doubt, however, that Britain's existing commitment to the EU is attracting an increasing level of legislative attention, which is insidiously impacting through the planning process year on year.

\section{THE FUTURE}

\section{Future government aims and objectives}

The government has now recognised that leisure and tourism development is a major pressure for land-use change. In April 1998, the Department of the Environment, Transport and the Regions (DETR) commissioned a two-stage research project studying how planning policy guidance for England could best facilitate leisure and tourism developments while achieving more sustainable patterns of development and travel. ${ }^{1}$ 
Stage 1 of the research considered planning for leisure, while stage 2 considered planning for tourism. It is interesting to note that even today the government draws a distinction between the two uses in planning terms, although from a practical perspective any distinction is becoming increasingly blurred.

The Report concludes that:

'Planners need to understand the sector's distinctive features and be aware of the trends and their implications given the potential for rapid change and likely sustained future growth in leisure and tourism ...

Planning Policy needs to reflect the special circumstances related to the impact of leisure and tourism - ie that:

- Leisure and tourism developments are major contributors to GDP and can act as catalysts in local economies.

- Travel for leisure and tourism generates a significant number of trips, predominantly by car. This is ameliorated by the relatively high occupancy of cars and their off-peak nature of trips.

- The environment and community impacts caused by leisure and tourism development are complex, including the vitality and viability of town centres, public amenity, the beneficial use of historic buildings and potential intrusion into rural, often sensitive areas...

Planning Policy is just one of a diverse range of potential Policy responses to these potential impacts; others include licensing and visitor management.'

This is a comprehensive study which highlights a wide range of findings, conclusions and recommendations too numerous to elaborate in detail. However, there are some key themes that flow through all sections of the study report.

The requirement to establish 'need'

The commercial leisure sector survives on creating, delivering to and maintaining market demand for its products. However, the planning system is increasingly more concerned with meeting 'needs' rather than creating or responding to simple public 'wants'; a difficult distinction to grasp for even the most altruistic of leisure developers. Perhaps not surprisingly, therefore, the researchers generally found considerable uncertainty over the definition and assessment of 'need'.

Current planning policy states that the requirement to demonstrate need should not be regarded as being fulfilled simply by showing that there is capacity or demand. However, the extent to which 'other factors' were brought to bear in determining need was found to be uncertain and uncoordinated. 


\section{A balance must be struck between leisure and more fundamental land uses}

\section{A growing awareness of value}

The report highlights that clarification is needed with regard to what other factors the definition of 'need' should cover, in addition to market capacity and physical capacity; for example, the effects on local leisure provision.

Of course, this lack of understanding extends to the authorities as well as leisure developers and operators. Arguably, most 'leisure' is discretionary and non-essential. It is a function of available funds and spare time. From a pure 'need' perspective, therefore, one could argue at the extreme that there is no overriding requirement to supply any leisure facilities at all. However, if local authorities are to avoid the possibility of major social unrest, a proper balance must be struck between providing opportunities for rest and play (both within and outside the urban environment) and the more urgent requirements of housing, employment and public services.

However, even in areas used to handling the demands of a large leisure market, authorities are often prescriptive in their approach through a lack of knowledge of the market, or an overly jaundiced perception of the industry. Committees can be too cautious in granting permission for development proposals that are out of the mainstream, or likely to attract local public concern (whether well founded or not). They can also be just as quick to seek credit for a successful scheme, even where the development has progressed despite the authority.

This somewhat jaundiced practitioner's view is becoming tempered by the slow, but apparent, awareness by authorities of the true economic value of tourism and leisure which is emerging at a local level, particularly in rural areas. The leisure sector is now being recognised as a valuable source of jobs and revenue, rather than an unappreciated add-on to mainstream development.

The dynamics of the leisure industry, affected by fashion as much as anything, result in rapid changes in the direction, scale and nature of leisure development. This creates an additional problem for planners who, through no fault of their own, can be left floundering. The local plan process cannot really tackle the changing demands of this sector through land allocation; the usual two- to four-year cycle from deposit to adoption can witness several changes in some sectors of the leisure market.

Unsurprisingly perhaps, the study recommends that further detailed, coordinated research is required to establish optimum means of assessment.

\section{Impact statements}

The report recommends that large leisure proposals (over $1,000 \mathrm{~m}^{2}$ ) should be required to prepare an impact statement including, where necessary, the economic justification for the inclusion of crosssubsidising elements of development.

At the extreme this may effectively require a complete rehearsal of development costs, funding mechanisms and sale and lease terms to be explored, with the potential for the whole scheme to be aired 


\section{All leisure to be directed towards town centres}

(and no doubt picked over for weaknesses and ideas) in the public domain.

\section{Sequential testing for all}

The report also recommends that, in line with government thinking, leisure development of all types and scales should be directed towards an appropriate town or district centre in line with the principles of Planning Policy Guidance Note (PPG) 6 (Town Centres and Retail Developments) and PPG13 (Transport).

Moreover, new approaches, underpinned by research, are recommended in order to measure the longer-term impact of outof-centre leisure developments on the vitality and viability of town centres. While the sequential test was considered to offer a rational, effective approach to planning for leisure, the research so far has established that a key constraint, identified by both the private and public sectors, was the lack of suitable sites, particularly in town centres.

The report notes that the sequential approach is not always applied to some leisure land uses, particularly public sector leisure facilities, restaurants and bars. It concludes, however, that there do not appear to be any overriding reasons to distinguish between different leisure land uses in terms of locational policy and therefore all leisure development should be directed towards an appropriate town or district centre in line with planning principles.

\section{'Developers should be required to demonstrate that they have used the sequential test when submitting planning applications.'}

The report goes on to recommend that local planning authorities should be encouraged to identify and/or assemble leisure development sites to meet identified need. In addition, the definition of what constitutes the 'town centre, edge of centre' etc should be established at the development plan stage.

Given what has already been said, can local authorities really grasp the diverse requirements of this sector by applying standard planning techniques and achieve any meaningful results? The leisure industry will have to take a much more proactive role in affecting the direction of future planning, delivering detailed statistics and market assessments and negotiating the minutiae of local plan policy on behalf of the industry. Perhaps the industry should invent the equivalent of the House Builders' Federation as a unified lobbying body for this sector.

There was overall support for a new leisure section within a revised PPG6 to provide further clarification rather than any change to the policy itself.

Disaggregation

Disaggregation of uses is already an emerging feature of today's 
Report found no real evidence of functional synergies
All elements of a mixed scheme could be sequentially tested planning system, and the report considers this in relation to leisure development. The researchers asked key questions regarding the scale of development and the functional relationship between leisure elements.

'Developers have claimed that there are various synergies between major leisure uses at multi-leisure destinations that encourage large scale developments.' (para. 12.17)

However, the consultants found from user surveys and consultations that there were relatively few multi-leisure activity trips and there did not appear to be any evidence of an overriding functional synergy between leisure uses within mixed leisure schemes. There were identifiable trends in repeat visits to different leisure uses at familiar centres (para. 12.18).

The report notes that this trend of repeat visits for singlepurpose leisure activity is just as applicable to town centres as it is for dedicated out-of-centre developments. The alleged need for large-scale leisure developments, based on inherent synergies, was thus found wanting.

The report therefore concludes that:

'This finding would support the principle of dis-aggregation ie the application of the sequential test to each major leisure element in a scheme.' (Conclusion c.18)

The report does go on to indicate that the scale of development can dictate financial viability, and that developers may be discouraged if schemes are insufficiently large to be commercially viable.

Nevertheless, the report recommends that:

'The sequential test should apply to individual elements of mixed leisure development schemes. However, there may be exceptional circumstances where financial issues justify the consideration of a large development or complex of facilities eg to allow for the cross-subsidy of a desirable but noncommercial element.' (Conclusion c.19)

If this recommendation is taken up, then all forms of commercial retail and leisure will be subject to sequential testing on each element of any scheme, and every part of any mixed scheme will need to be separately justified, unless special circumstances can be argued.

Recommendation R6 states:

'Current policy relating to dis-aggregation of uses should be reinforced as a key principle of PPG6. Exceptions may be made to support an identified development priority.'

How the demands of sequential testing and the emerging 
Can regional guidance really manage leisure development? philosophy of disaggregation would combine to deliver meaningful leisure development within urban and rural areas remains open to considerable speculation.

\section{Regional guidance and development plans}

Regional planning guidance (RPG) is encouraged to make specific reference to the planning requirements for major leisure development, and there was encouragement for local authorities to coordinate and prepare background research and capacity studies where appropriate.

The study found that RPG 'currently contributes little to planning for leisure', and therefore asks whether there is a role to be played. Although PPG11 sets out the requirements for developing a comprehensive spatial strategy for a region, the current PPG offers little in the way of guidance concerning leisure.

Case study evidence suggested that a sub-regional review would help to 'secure the most appropriate development in the most appropriate location, in terms of impact, minimising the overall need to travel and maximising accessibility by a variety of means of transport'.

The overall aim would be to avoid the proliferation of competing schemes within a sub-region through closer cooperation between authorities in their decision-making processes. In this way even in rural areas 'development in one location would pre-empt development in other towns' where two similar proposals may be uneconomic.

The trouble is, the leisure sector is a fundamentally competitive market. It thrives on providing diversity and variations on a theme. While there may be some scope for controlling the excesses of the industry in terms of over-provision, this philosophy may only work at the macro level.

As far as development plans are concerned, the report concludes that leisure needs more comprehensive, specific and detailed consideration, taking into account policies in PPG6 and PPG13, and that sites need to be allocated for the different types of leisure development proposed.

The report recommends that leisure applications which do not accord with the provisions of a development plan should attract an appropriate leisure impact assessment, to include an assessment of local capacity, transport and environmental impact, and issues of vitality and viability of the town centre.

A key determinant for future leisure development will involve relationships with the transport infrastructure. Minimising car journeys and maximising the use of public transport will remain a fundamental issue, both at regional and sub-regional/local levels. The report tends to assume that the requirements of PPG13 will apply across the board, and the likely effects of transport issues for the leisure industry should not be underestimated. 
An over prescriptive approach to leisure could be destructive
The report cites evidence of competition between authorities in the attraction of leisure developments and encourages a more cooperative stance. Can this really be a likely outcome? Will local authority A forgo a beneficial scheme for its residents (voters) and allow local authority B to benefit, in the interests of sustainability and regional cohesiveness? How will transport links affect the overall accessibility from both sides of the fence? There are clearly complex issues to be overcome in addressing the competing demands of planning for leisure.

Rural businesses in particular may be increasingly constrained through lack of public transport accessibility, and this may in the longer term have profound effects upon the vitality and viability of the countryside. While at the present time tourism is seen as a potential saviour of the rural economy, will an over-prescriptive approach to reducing car-borne travel sow the seeds of destruction for the future? Maybe the increasing price of fuel will achieve this without the planners' involvement in any event; and what then?

Here again, an early and purposeful industry involvement in the processes of defining regional strategies for more local application must be a minimum requirement.

\section{Use Classes Order changes}

With regard to A3 development (Food and Drink), the study supports proposals made by the National Planning Forum for changes to the basis of the Use Classes Order, creating a better definition and distinction between different elements. Similarly, the report recommends that local planning authorities take a proactive lead in coordinating and developing partnerships for the future management and development control of A3 and D2 (Assembly and Leisure) uses.

As far as tourism development is concerned, the report recommends that Planning Policy Guidance Note PPG21 (Tourism) should be brought up to date to reflect better the special nature of tourism land uses and sustainable development principles. Here again, capacity assessments are recommended as well as urban concentration for major travel generators, although there is an acknowledgement that some flexibility should be given to those tourist facilities whose location is not footloose.

The study concludes that:

\section{'It is recommended that the Use Classes Order $\left(A_{3}\right)$ is changed on the basis of the proposals made by the NPF.' (R.26)}

These issues are currently the subject of a DETR research project to examine the wider amenity, environmental and planning effects of changes of use.

Hotels

As far as hotels are concerned, these should be treated as town- 
Planning is fast becoming the principal determinant of future leisure development centre uses and subject to the principles of PPG6. Local planning authorities are encouraged to identify and/or assemble hotel development sites in the context of identified need. However, small hotels need to be treated more flexibly, but with the emphasis on town and district centres or a location generally within built-up areas.

Planning for tourism is not simply concerned with development control issues, but involves a consideration of all land uses and activities that go into making a tourism destination. Helpfully, the report recommends that local authorities are encouraged to cooperate and facilitate appropriate partnership groups for effective tourism planning and visitor management alongside amended planning policies. It is for the industry to be proactive in developing these partnerships to progress its future within the planning-driven development market.

\section{WHERE CAN THE LEISURE INDUSTRY GO FROM HERE?}

The government is clearly progressing its urban agenda across all property sectors, driven and dictated by the planning system. There is little or no likelihood that the plan-led system will be materially weakened in years to come. Rather, planning is fast becoming the principal determinant of future leisure development.

Increasing competition for brownfield sites and the more complex and time-consuming processes for enabling development through the development plan process may hinder many schemes and slow the more dynamic elements of the leisure industry.

Local planners are increasingly likely to be allocating sites for specific leisure uses within local plans, having regard to planning guidance, but perhaps with less regard to individual market requirements. For example, the number of allocated (but as yet undeveloped) hotel sites around the country stands testament to an insufficiently briefed or overly optimistic planning system. But this is as much the fault of leisure being a very diverse industry.

For all leisure uses sequential testing, need, capacity and environmental assessments are likely to be the order of the day. If accepted, the findings of this study suggest that mixed-leisure schemes, whether in or out of town, will have to be justified on an elemental basis, with disaggregation the fundamental underlying philosophy.

Equally, the requirements of minimising travel by car will increasingly affect the locational requirements of leisure schemes, in direct competition for scarce sites with all other forms of development. Land price issues are therefore likely to constrain the leisure sector further.

The recent foot-and-mouth crisis may moderate the government's approach to certain aspects of leisure development in the countryside, particularly where it can be demonstrated that a proposal will lend valuable support to the rural economy. However, this is a short-term phenomenon and the future of rural leisure 
development may be more crucially determined over the longer term by the structural shift in the planning system.

It is difficult, if not impossible, for the leisure industry to speak with a single voice; nor should it attempt to do so, given the wide diversity of interests encapsulated within that one term.

Nevertheless, the author believes there is a need for some unification of approach, particularly with regard to the future allocation of scarce land resources and the interpretation of any redrafted PPGs and development plan policy.

The leisure industry has benefited (and to some extent suffered) from a largely inadequate policy framework over the last decade. This situation is scheduled to change, and the industry should be ready to respond. The plan-led system will remain and develop. The industry should therefore be in the driving seat of proposals and debate into future development plans, both to ensure that the industry is properly understood and reflected in policy terms and to mark its place for what will become increasingly scarce urban development sites.

The outlook is not bleak, but it is changing, and the industry must change with it or risk losing out to those sectors already immersed in their plan-led futures.

\section{References}

1. DETR (2001) The Research Report on Planning for Leisure and Tourism, Executive Summary, www.planning.detr.gov.uk/rropflat/summary.htm. 